\title{
Intravenous insulin has no effect on myocardial contractility or heart rate in healthy subjects
}

\author{
J. Airaksinen, J.T. Lahtela, M.J. Ikäheimo, E. A. Sotaniemi and J. T. Takkunen \\ Cardiovascular Division and Clinical Research Unit, Department of Medicine, Oulu University Central Hospital, Oulu, Finland
}

\begin{abstract}
Summary. To evaluate the acute effects of intravenous insulin on myocardial contractility and heart rate, echocardiography was performed in 12 healthy subjects and continuous heart rate recording in 11 healthy subjects before and during euglycaemic insulin and glucose infusion. The rate of insulin infusion was $0.5-1.0 \mathrm{mU} \cdot \mathrm{kg}^{-1} \cdot \mathrm{min}^{-1}$. Serum insulin concentration was increased from $14.1 \pm 5.5$ (mean \pm SD) to a plateau level of $91.3 \pm 22.8 \mathrm{mU} / 1$. Left ventricular end-diastolic di-
\end{abstract}

ameter, ejection phase indices and the heart rate remained at basal levels during the intervention. Thus moderate hyperinsulinaemia, induced by euglycaemic insulin and glucose infusion, has no inotropic or chronotropic effects in healthy supine subjects.

Key words: Insulin, myocardial contraction, heart rate, diabetes mellitus.
Intravenous insulin has been claimed to increase heart rate in normal subjects and in patients with diabetes mellitus, particularly in the upright position [1-5]. Experimental studies on lambs and cats have shown that intravenous insulin increases myocardial contractility, an effect which was not dependent on glucose or catecholamines [6-7]. However studies on dogs and rats have failed to demonstrate a positive inotropic effect in either intact hearts or isolated cardiac muscle [8-10]. In patients with myocardial infarction combined glucoseinsulin-potassium infusion improves global ejection fraction and ejection fraction in the ischaemic zone [11]. Insulin-induced hypoglycaemia is also associated with marked inotropic and chronotropic effects in man [12].

The purpose of the present study was to evaluate whether intravenous insulin has any acute effects on myocardial contractility and heart rate in healthy subjects. In contrast to most previous studies we used the euglycaemic clamp technique to avoid a decrease in blood glucose levels, which might activate counter-regulatory systems and so indirectly affect cardiac function.

\section{Subjects and methods}

\section{Subjects}

Seventeen healthy medical students (12 men, 5 women), aged 21-34 years (mean 24 years), volunteered for the study and gave informed consent. The protocol was approved by the Ethical Commit- tee of Oulu University. Subjects were physically fit (many of them sports enthusiasts) and none had a family history of diabetes. Their body mass indices ranged from 16.8 to $24.7 \mathrm{~kg} / \mathrm{m}^{2}$ (mean $22.0 \mathrm{~kg} / \mathrm{m}^{2}$ ).

\section{Hyperinsulinaemia}

Acute hyperinsulinaemia was achieved with the euglycaemic clamp technique [13] as described previously [14]. Subjects were studied in the postabsorptive state after an overnight fast and $1 \mathrm{~h}$ supine rest. An intravenous cannula was inserted into an antecubital vein for glucose and insulin infusions. A second catheter was inserted into a dorsal hand vein of the opposite hand for blood sampling. A loading dose plus a continuous infusion of crystalline semi-synthetic human insulin (Actrapid HM, Novo, Copenhagen, Denmark) was given. The loading dose was infused in a logarithmically decreasing manner for $10 \mathrm{~min}$ to reach a hyperinsulinaemic level. The continuous infusion of insulin was begun at $10 \mathrm{~min}$ and continued up to $120 \mathrm{~min}$ to maintain hyperinsulinaemia. The rate of continuous insulin infusion was $0.5-1.0 \mathrm{mU} \cdot \mathrm{kg}^{-1} \cdot \mathrm{min}^{-1}$. This protocol results in an initial overshoot in plasma insulin concentration that lasts about $20 \mathrm{~min}$ and is followed by a plateau plasma insulin level [13]. The blood glucose was maintained at the euglycaemic level by the determination of blood glucose every $5 \mathrm{~min}$ and adjustment of the infusion rate of a $20 \% \mathrm{glu}$ cose solution. Samples for serum immunoreactive insulin determinations were taken before the infusion and every $10 \mathrm{~min}$ during the infusion, starting $20 \mathrm{~min}$ after the onset of infusion.

\section{Chemical methods}

Blood glucose concentration was determined immediately using a reflolux strip test (BM-Test-BG, Boehringer Mannheim, Mannheim, FRG), and checked with a hexokinase method (Glucoquant, Boehringer Mannheim). Serum insulin concentration was determined by a RIA kit (Coat-A-Count, Diagnostic Products Corporation, Los Angeles, California, USA). Plasma concentrations of noradrenaline and 
adrenaline were determined by radioenzymatic assay [15] in 6 subjects ( 4 of whom took part in the echocardiographic study) before and at 30 min after the beginning of insulin infusion.

\section{Echocardiography}

Echocardiography was performed in 12 of the subjects (8men, 4 women) immediately before and at 10,20,30 min (and $60 \mathrm{~min}$ in
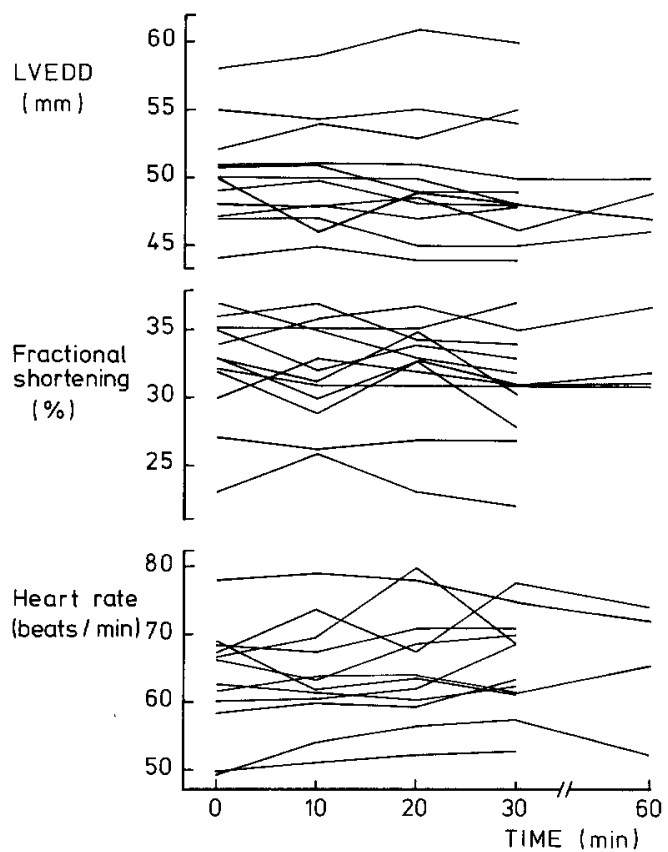

Fig. 1. Left ventricular end-diastolic diameter (LVEDD), fractional shortening of the minor axis and heart rate determined from the R-R intervals of the echocardiograms in 12 healthy subjects before and during insulin infusion
4 subjects) after the beginning of the insulin infusion. Echocardiograms were obtained with an ATL Mark III real-time echocardiographic system (Bellevue, Washington, USA) using a mechanical sector transducer with a $90^{\circ}$ angle and a frequency of $3.0 \mathrm{mHz}$. The Mmode echocardiogram, ECG, and a carotid pulse tracing were recorded with a fibreoptic recorder (Honeywell, Denver, Colorado) on ultraviolet paper with a speed of $100 \mathrm{~mm} / \mathrm{s}$ using an accurate standard technique routinely employed in this laboratory [16]. By reviewing previous records, similar sites just distal to the tip of the anterior mitral leaflet were selected for serial measurements. The left ventricular end-diastolic diameter (LVEDD) and end-systolic diameter (LVESD) were measured according to the recommendations of the American Society of Echocardiography [17]. The fractional shortening of the left ventricular minor axis in systole was calculated as (LVEDD-LVESD) $\times 100 /$ LVEDD and the mean velocity of the left ventricular circumferential fibre shortening as (LVEDD-LVESD)/ LVEDD $\times$ LVET, where LVET is left ventricular ejection time measured from the simultaneously recorded carotid pulse tracing. Heart rate during echocardiographic recordings was derived from the R-R intervals on the ECG. All measurements were made from approximately 10 consecutive or nearly consecutive cardiac cycles without knowing the subject's clinical data. The difference between duplicate echocardiographic measurements $(n=28)$ was as follows: LVEDD, $0.6 \pm 0.7 \mathrm{~mm}$; fractional shortening of minor axis, $1.4 \pm 1.4 \%$; mean velocity of circumferential fibre shortening, $0.05 \pm 0.04$ circumference $\cdot \sec ^{-1}$.

\section{Heart rate recording}

Continuous heart rate recording was performed in a supine position in 11 subjects ( 7 men, 4 women), six of whom also took part in the simultaneous echocardiographic study. The heart rate was determined with a microcomputer pulse transmitter (Sport Tester PE 2000, Polar Electro, Kempele, Finland), which continuously measures the heart rate and records the data in memory for later analysis and processing [18]. From these data the mean heart rate of successive 10-min periods was determined in each subject. Heart rate monitoring was started $20 \mathrm{~min}$ before the insulin infusion, when the catheters were inserted and when the subjects had already rested at least $30 \mathrm{~min}$ in a supine position.

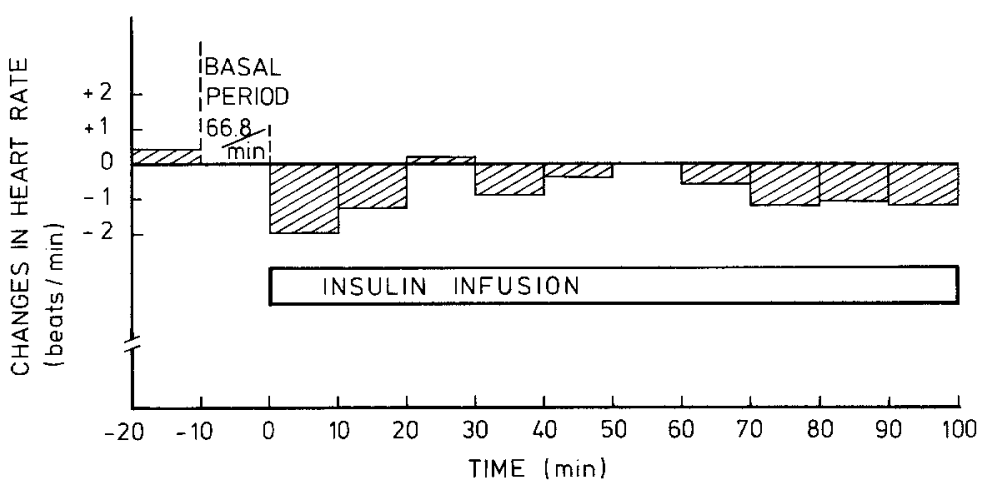

Fig. 2. The mean heart rate of successive 10 -min periods in 11 healthy subjects before and during insulin infusion

Table 1. Echocardiographic data and blood pressure in 12 healthy subjects before and during insulin infusion

\begin{tabular}{|c|c|c|c|c|c|}
\hline \multirow[b]{3}{*}{ Left ventricular end-diastolic diameter (mm) } & \multirow[t]{2}{*}{ Basal } & \multicolumn{4}{|c|}{ Infusion time (min) } \\
\hline & & $\overline{10}$ & 20 & 30 & $60(n=4)$ \\
\hline & $50 \pm 4$ & \pm 4 & \pm 5 & \pm 5 & \pm 2 \\
\hline Left ventricular shortening fraction (\%) & \pm 4 & $32 \pm 4$ & \pm 4 & $31 \pm 4$ & $33 \pm 3$ \\
\hline $\begin{array}{l}\text { Mean velocity of circumferential fibre shortening } \\
\text { (circumference } \cdot \mathrm{sec}^{-1} \text { ) }\end{array}$ & $1.05 \pm 0.11$ & $1.04 \pm 0.11$ & $1.07 \pm 0.14$ & $1.03 \pm 0.14$ & $1.08 \pm 0.12$ \\
\hline Heart rate (beats/min) & \pm 8 & \pm 8 & \pm 8 & \pm 7 & \pm 10 \\
\hline Systolic blood pressure $(\mathrm{mmHg})$ & $122 \pm 15$ & \pm 13 & \pm 14 & \pm 14 & \pm 11 \\
\hline Diastolic blood pressure (mmHg) & $79 \pm 10$ & $76 \pm 11$ & $77 \pm 10$ & $77 \pm 13$ & $69 \pm 9$ \\
\hline
\end{tabular}

Results expressed as mean $\pm \mathrm{SD}$ 


\section{Statistical analysis}

Differences between repeated measurements were tested using the non-parametric statistical method of Friedman two-way analysis of variance and the Wilcoxon test. All data are expressed as mean \pm SD.

\section{Results}

The insulin infusion raised the serum insulin concentration from $14.1 \pm 5.5$ to a plateau level of $91.3 \pm$ $22.8 \mathrm{mU} / 1$. The blood glucose level during the intervention was $4.9 \pm 0.4 \mathrm{mmol} / 1$ with a coefficient of variation of $7.3 \pm 2.1 \%$. The mean volume of glucose infused during the first $30 \mathrm{~min}$ was $87 \pm 20 \mathrm{ml}$ and during the subsequent 30 min periods $105 \pm 26 \mathrm{ml}$.

In the echocardiographic study of 12 subjects, left ventricular end-diastolic diameter and the ejection phase indices remained at basal levels during the insulin infusion (Table 1, Fig.1). Continuous heart rate recording in 11 subjects revealed no change in heart rate during the infusion (Fig. 2).

No significant changes in plasma concentrations of catecholamines were observed. The adrenaline concentration before insulin infusion was $0.23 \pm 0.05$ and during the infusion $0.24 \pm 0.06 \mathrm{nmol} / 1$. The noradrenaline concentrations were $1.81 \pm 0.49$ and $1.70 \pm 0.50 \mathrm{nmol} / 1$ respectively.

\section{Discussion}

Evaluation of the effects of insulin on cardiovascular function is complex, since insulin may influence cardiac function through several indirect mechanisms. Hypoglycaemia, or even a slight decrease in blood glucose levels, may activate glucose counter-regulatory systems [19]. Furthermore high doses of intravenous insulin increase plasma noradrenaline independent of changes in blood glucose [3]. Insulin also impairs the inotropic action of noradrenaline on the heart [7]. The insulin-induced reduction in effective circulatory blood volume may also increase heart rate, particularly in the upright position. Reports concerning plasma volume changes are, however, conflicting and the observed reductions may be secondary to $\alpha$-adrenergic stimulation [12, 20-22].

To avoid these indirect effects of insulin we produced hyperinsulinaemia using euglycaemic glucose and insulin infusion. The insulin infusion level employed was comparable to that recommended for patients with myocardial infarction [11] and was not so high as to induce an elevation in plasma catecholamines [19]. Myocardial contractility was assessed by M-mode echocardiography, which has the limitation of monitoring only a small part of the left ventricle. It is, however, a reproducible standard technique suitable for serial studies in young subjects such as these, since they all had high quality recordings and symmetrical wall mo- tions in simultaneous two-dimensional study [23-24]. A relatively short echocardiographic observation time was chosen, since earlier experimental and clinical studies have shown a maximal cardiac effect within $30 \mathrm{~min}$ of insulin administration $[6-7,12]$.

Fractional shortening of the left ventricular minor axis and the mean velocity of circumferential fibre shortening directly reflect myocardial contractility, since neither pre-load (left ventricular end-diastolic diameter), after-load (systolic blood pressure) nor heart rate changed significantly during the recordings (Table 1). These ejection phase indices remained virtually unchanged throughout the intervention and the minor fluctuations in the values were within the limits of reproducibility (Fig.1) [23, 25]. Plasma volumes were not determined in these subjects, but the unchanged left ventricular end-diastolic diameter suggests indirectly that no marked change in effective plasma volume occurred during the infusion [26].

Rowe et al. [3] measured the heart rate using an arm cuff technique at regular intervals in 12 healthy subjects and observed a heart rate rise of $0-7.5$ beats $/ \mathrm{min}$ during $2 \mathrm{mU}$ and $5 \mathrm{mU}$ euglycaemic insulin infusions. In contrast to their findings no insulin-induced increase in heart rate was observed in these healthy subjects. Differences in measuring technique and in insulin doses may explain the discrepancy.

Earlier studies in diabetic subjects have demonstrated a heart rate rise of $4-9$ beats/min after intravenous insulin without a euglycaemic clamp technique [1, $2,4]$. At least two factors may contribute to the difference in the heart rate response to insulin between diabetic and healthy subjects. Firstly a decreasing blood glucose level, even without hypoglycaemia, may activate the glucose counter-regulatory systems of diabetic subjects which alone may raise the heart rate [19]. Secondly it is possible that the cardiovascular effects of insulin are dependent on the pre-existing insulin level. Hence responses observed during insulin deficiency may not be applicable in healthy subjects. This might, together with a wide range of insulin doses, also explain the variable inotropic responses observed in experimental studies dealing with either non-diabetic or alloxandiabetic insulin-deficient animals $[6,9,27]$. It is questionable that the use of human insulin contributed to our negative findings although pork insulin and mixed beef-pork inulin preparations have been shown to have divergent inotropic actions in experimental studies [28].

In conclusion, moderate hyperinsulinaemia, induced by intravenous insulin infusion with a euglycaemic clamp technique, had no inotropic or chronotropic effects in healthy supine subjects. Our negative findings do not exclude potential cardiovascular effects of higher, supraphysiological hyperinsulinaemia which also results in a rise in plasma catecholamines.

Acknowledgement. This study was supported by a grant from Oy Hoechst Fennica Ab. 


\section{References}

1. McB Page M, Smith RBW, Watkins PJ (1976) Cardiovascular effects of insulin. Br Med $\mathrm{J} 1$ : 430-432

2. Christensen NJ, Gundersen HJG, Hegedus L, Jacobsen F, Mogensen CE, Österby R, Vittinghus E (1980) Acute effects of insulin on plasma noradrenaline and the cardiovascular system. Metabolism 29: (Suppl 1): 1138-1144

3. Rowe JW, Young JB, Minaker KL, Stevens AL, Palotta J, Landsberg L (1981) Effect of insulin and glucose infusions on sympathetic nervous system activity in normal man. Diabetes 30 : 219-225

4. Mogensen CE, Christensen NJ, Gundersen HJG (1980) The acute effects of insulin on heart rate, blood pressure, plasma noradrenaline and urinary albumin excretion. The role of changes in blood glucose. Diabetologia 18: 453-457

5. Miles DW, Hayter CJ (1968) The effect of intravenous insulin on the circulatory responses to tilting in normal and diabetic subjects with special reference to baroreflex block and atypical hypoglycaemic reactions. Clin Sci 34: 419-430

6. Downing SE, Lee JC (1979) Myocardial and coronary vascular responses to insulin in the diabetic lamb. Am J Physiol 237: H514-519

7. Lee JC, Downing SE (1976) Effects of insulin on cardiac muscle contraction and responsiveness to norephinephrine. Am J Physiol 230: 1360-1365

8. Lucchesi BR, Medina M, Kniffen FJ (1972) The positive inotropic action of insulin in the canine heart. Eur J Pharmacol 18: 107-115

9. Schaible TF, Malhotra A, Bauman WA, Scheuer J (1983) Left ventricular function after chronic insulin treatment in diabetic and normal rats. J Mol Cell Cardiol 15: 445-458

10. Regan TJ, Frank MJ, Lehan PH, Hellems HK (1963) Relationship of insulin and strophanthidin to myocardial metabolism and function. Am J Physiol 205: 790-794

11. Whitlow PL, Rogers WJ, Smith LR, McDaniel HG, Papapietro SE, Mantle JA, Logic JR, Russell RO, Rackley CE (1982) Enhancement of left ventricular function by glucose-insulin-potassi$\mathrm{um}$ infusion in acute myocardial infarction. Am $\mathbf{J}$ Cardiol 49: $811-820$

12. Hilsted J, Bonde-Petersen F, Norgaard M-B, Greniman M, Christensen NJ, Parving H-H, Suzuki M (1984) Haemodynamic changes in insulin-induced hypoglycaemia in normal man. Diabetologia $26: 328-332$

13. DeFronzo RA, Tobin JD, Andres R (1979) Glucose clamp technique: a method for quantifying insulin secretion and resistance. Am J Physiol 237: E214-223

14. Lahtela JT, Arranto AJ, Sotaniemi EA (1985) Enzyme inducers improve insulin sensitivity in non-insulin dependent diabetics. Diabetes (in press)

15. Peuler J, Johnson G (1977) Simultaneous single isotope radioenzymatic assay of plasma norepinephrine, epinephrine and dopamine. Life Sci 21: 625-636
16. Feigenbaum H (1972) Echocardiography. Lea \& Febiger, Philadelphia, pp 37 39

17. Sahn DJ, DeMaria A, Kisslo J, Weyman A (1978) Recommendations regarding quantitation in M-mode echocardiography: results of a survey of echocardiographic measurements. Circulation 58: $1072-1083$

18. Säynäjäkangas S (1984) Microcomputers for sportsmen. High technology from Finland. The Finnish Academy of Technical Sciences, Helsinki, Finland, pp 58-59

19. DeFronzo RA, Hendler R, Christensen N (1980) Stimulation of counterregulatory hormonal responses in diabetic man by a fall in glucose concentration. Diabetes 29: 125-131

20. Gundersen HJG, Christensen NJ (1977) Intravenous insulin causing loss of intravascular water and albumin and increased adrenergic nervous activity in diabetics. Diabetes 26: 551-557

21. Parving H-H, Noer I, Deckert T, Lassen NA (1979) Intravenous insulin has no effect on transcapillary escape rate of albumin and on plasma volume in short-term juvenile diabetics. Diabetes 28 : 282-286

22. MacKay JD, Hayakawa H, Watkins PJ (1978) Cardiovascular effects of insulin: Plasma volume changes in diabetics. Diabetologia 15: 453-457

23. Clark RD, Korcuska K, Cohn K (1980) Serial echocardiographic evaluation of left ventricular function in valvular disease, including reproducibility guidelines for serial studies. Circulation 62 : 564-575

24. Popp RL (1982) M mode echocardiographic assessment of left ventricular function. Am J Cardiol 49: 1312-1318

25. Ikäheimo M (1977) Re-evaluation of echocardiography in preoperative assessment and postoperative follow-up of rheumatic mitral valve disease. Thesis, University of Oulu, Finland

26. Buch J, Egeblad H, Hansen PB, Kjaergard H, Waldorf S, Steiness E (1980) Correlation between changes in systolic time intervals and left ventricular and-diastolic diameter after preload reduction. Non-invasive monitoring of pharmacological intervention. Br Heart J 44: 668-671

27. Rubinstein M, Schaible TF, Malhotra A, Scheuer J (1984) Effects of graded insulin therapy on cardiac function in diabetic rats. Am J Physiol 246: H453-458

28. Farah AE, Alousi AA (1981) The actions of insulin on cardiac contractility. Life Sci 29:975-1000

Received: 27 December 1984

and in revised form: 20 May 1985

Dr. J. Airaksinen

Cardiovascular Division, Department of Medicine

Oulu University Central Hospital

SF-90220 Oulu

Finland 